\title{
Organization of Interrelated Aromatic Metabolic Pathway Enzymes in Acinetobacter calco-aceticus
}

\author{
By MARY B. BERLYN AND N. H. GILES* \\ Department of Biology, Yale University, New Haven, Connecticut 065I 7, U.S.A.
}

(Received I I July 1972)

\section{INTRODUCTION}

In Neurospora crassa and several other fungi, five sequential steps in the common aromatic biosynthetic pathway are catalysed by a multi-enzyme complex, encoded in a gene cluster (Giles, Case, Partridge \& Ahmed, I967a; Ahmed \& Giles, I969). In contrast, in bacteria the corresponding enzymes are for the most part separable, of low molecular weight and not encoded in a gene cluster (Berlyn \& Giles, I969). It has been suggested that the occurrence of the complex is related to the existence of a hydroaromatic degradative pathway which shares three metabolites and one enzymatic reaction with the aromatic biosynthetic pathway; competition for substrates would be alleviated by channelling the biosynthetic intermediates within the multi-enzyme complex (Giles, Partridge, Ahmed \& Case, 1967b). However, the multi-enzyme complex and the degradative pathway do not always occur together (Ahmed \& Giles, 1969; Berlyn \& Giles, 1969). The reports by Cánovas and coworkers (e.g. Tresguerres, deTorrontegui \& Cánovas, I970 $a$; Ingledew, Tresguerres \& Cánovas, 1971) concerning the occurrence and regulation of the hydroaromatic pathway in the moraxella species, Acinetobacter calco-ceticus, led us to examine the physical state of the biosynthetic enzymes in this organism. The pathways (cf. Giles et al. 1967 b) are shown overleaf: the upper reaction sequence $(a)$ leads to the eventual formation of acetyl CoA and succinate and the lower sequence $(b)$ to the aromatic amino acids and vitamins.

\section{METHODS}

Acinetobacter calco-aceticus strain 73 originated from the Collection of the Department of Bacteriology and Immunology, University of California, Berkeley, U.S.A., and was obtained from Dr José Cánovas, Instituto de Biologia Celular, C.S.I.C. Madrid, Spain. Bacteria were grown in $500 \mathrm{ml}$ of liquid minimal medium as used for Pseudomonas (Ornston \& Stanier, 1966) containing either $20 \mathrm{~mm}$-succinate, Io mM-quinate or a combination of $20 \mathrm{~mm}$-succinate and $2 \mathrm{~mm}$-quinate in $2800 \mathrm{ml}$ Fernbach flasks on a rotary shaker at $30{ }^{\circ} \mathrm{C}$.

The extraction buffer was $\mathrm{O}^{\circ} \mathrm{I} \mathrm{M}$-potassium phosphate, $\mathrm{pH} 7 \cdot 4$, containing $2 \times 10^{-4} \mathrm{M}$ dithiothreitol and $\mathrm{IO}^{-3} \mathrm{M}$-ethylenediaminetetraacetic acid. In some cases $\mathrm{O} \cdot \mathrm{I} \mathrm{M}-\mathrm{KCl}$ was included in both the buffer and the sucrose gradients. Several extraction procedures were used: bacteria suspended in buffer were subjected to sonic disintegration; frozen pellets were broken in a Hughes pressure cell at $98 \mathrm{MN} / \mathrm{m}^{2}\left(17000 \mathrm{lb} / \mathrm{in}^{2}\right)$ and suspended in buffer; bacterial suspensions were treated with lysozyme and subjected to osmotic shock as described by Tresguerres et al. (I970a). After disruption, suspensions were centrifuged at $27000 \mathrm{~g}$ for $30 \mathrm{~min}$ and the supernatant was either dialysed and used as a crude enzyme preparation or treated with $\mathrm{I} / \mathrm{IO}$ volume of $\mathrm{I} \cdot 4 \%(\mathrm{w} / \mathrm{v})$ protamine sulphate, fractionated

* Present address: Department of Zoology, University of Georgia, Athens, Georgia 3060 I, U.S.A. 
Quinic acid (QA)

Shikimic acid (SA)

Protocatechuic acid (PCA)

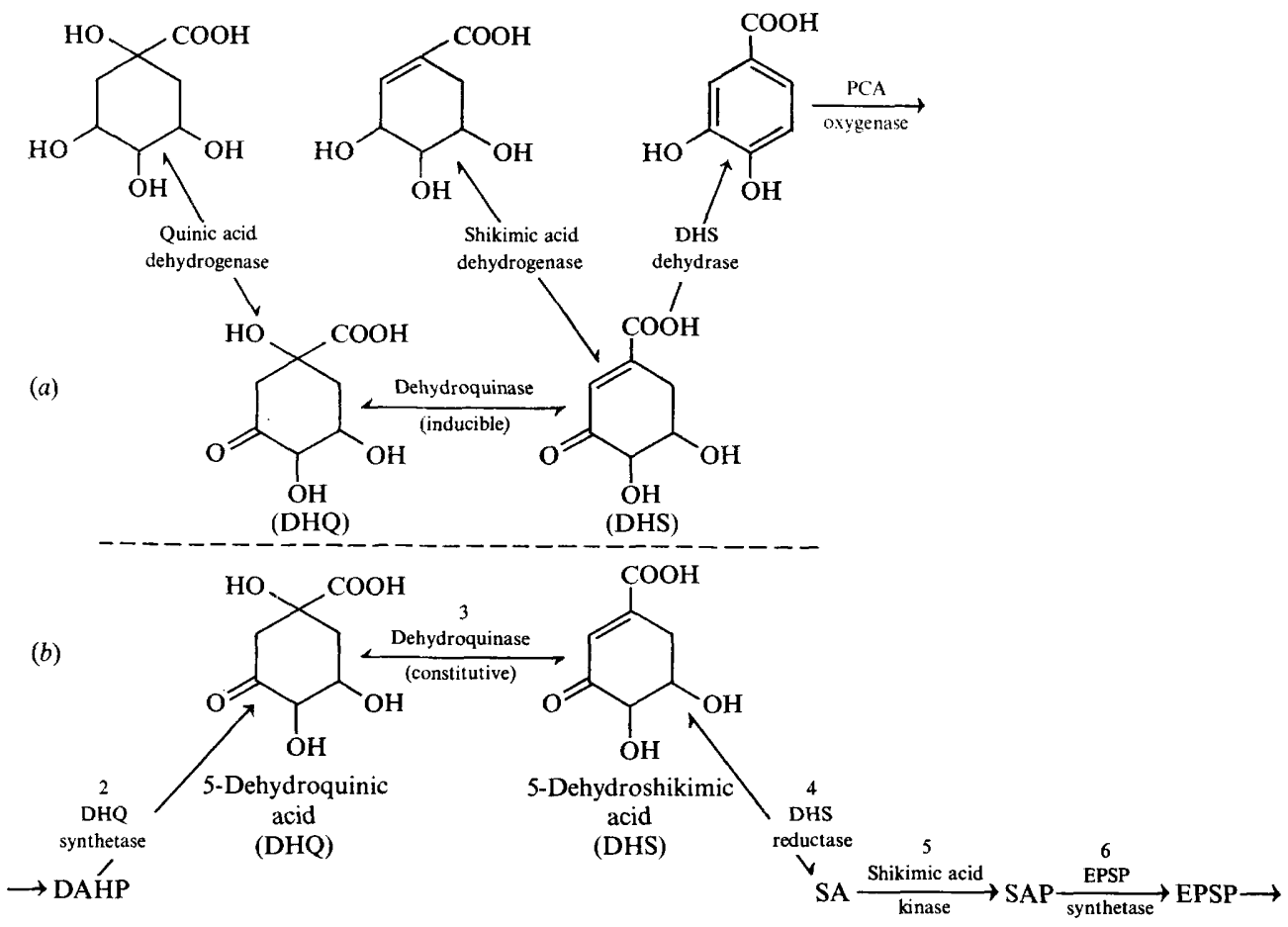

DAHP : 3-deoxy-D-arabinoheptulosonic acid-7- $\mathrm{PO}_{4}$

SAP: shikimic acid-5- $\mathrm{PO}_{4}$

EPSP: 3-enolpyruvylshikimic acid-5- $\mathrm{PO}_{4}$

with ammonium sulphate, and dialysed. Procedures for sucrose density-gradient centrifugation and enzyme assays have been described previously (Berlyn \& Giles, I969; Berlyn, Ahmed \& Giles, 1970). Gradients were centrifuged at $105000 \mathrm{~g}$ for I $5 \mathrm{~h}$.

\section{RESULTS}

The sedimentation patterns for the enzymes are shown in Fig. I. The various methods of extraction and the use of crude or fractionated preparations did not alter the observed patterns. These enzymes occurred in vitro as distinct, rather low molecular weight proteins rather than as a multi-enzyme complex.

Two dehydroquinase isozymes were observed: a light, heat-labile enzyme found in quinate-grown bacteria (Fig. I $a$ ) and a heavy, heat-stable enzyme found in both quinateand succinate-grown bacteria (Fig. I $a, b$ ). The average molecular weight values based on calculations from several sucrose gradients were: DHQ synthetase, 60000; biosynthetic dehydroquinase, 125000; inducible, degradative dehydroquinase, 41000; DHS reductase, 26000 ; shikimate kinase, I3000; EPSP synthetase, 44000. 


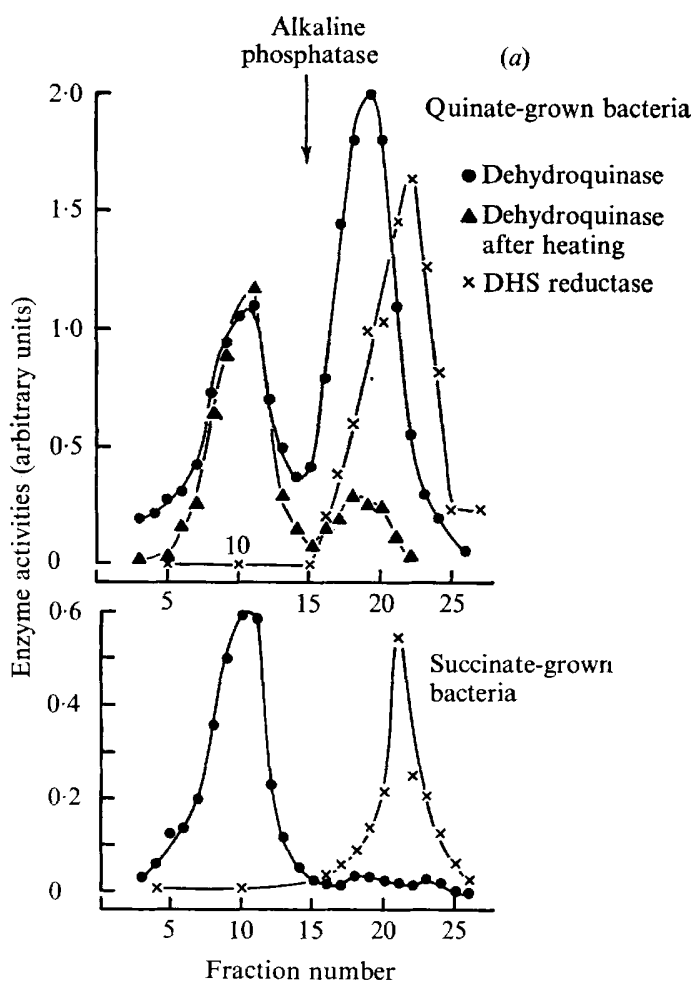

(b)

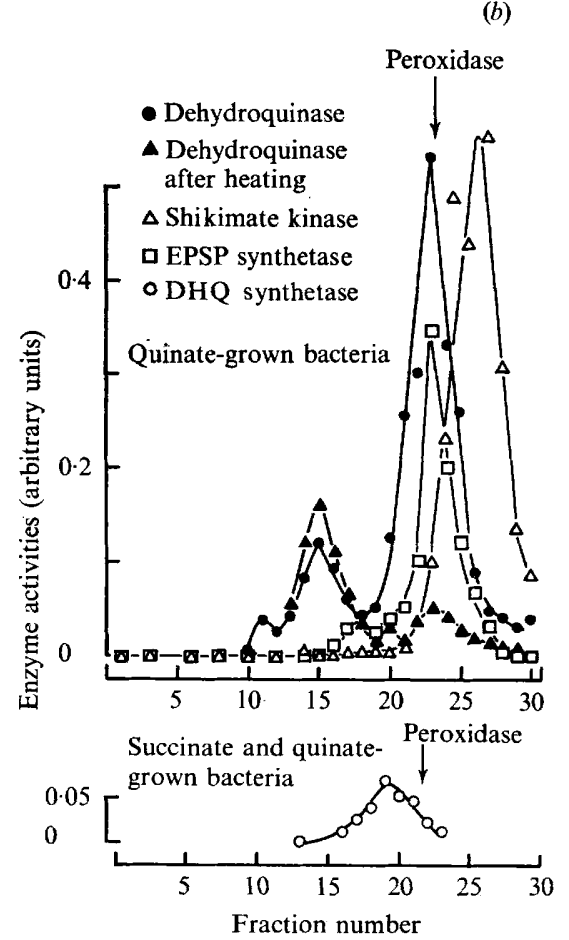

Fig. I. Distribution of aromatic enzyme activities after sucrose density gradient centrifugation of extracts of Acinetobacter calco-aceticus. (a) Distribution of DHS reductase and dehydroquinase in crude extracts of bacteria grown on quinate (above) or succinate (below). The gradient from the extract of the quinate-grown bacteria was heated at $70{ }^{\circ} \mathrm{C}$ for $10 \mathrm{~min}$ and its dehydroquinase activity after heating is also shown. Arrow indicates peak of activity for the enzyme standard, Escherichia coli alkaline phosphatase (mol. wt 80000). (b) Distribution of shikimate kinase, EPSP synthetase and dehydroquinase before and after heating (at $70^{\circ} \mathrm{C}$ for $10 \mathrm{~min}$ ) a gradient of a 0 to $50 \%$ ammonium sulphate fraction of bacteria grown on quinate, and DHQ synthetase activity from a comparable gradient of a similar extract of bacteria grown on a combination of $20 \mathrm{~mm}$-succinate and $2 \mathrm{~mm}$-quinate. Arrow indicates peak of activity for the enzyme standard, horseradish peroxidase (mol. wt 40000).

\section{DISCUSSION}

It has been suggested (Tresguerres, Ingledew \& Cánovas, 1972) that in Acinetobacter calco-aceticus the regulatory mechanism necessary for protecting aromatic biosynthetic intermediates in the presence of inducible enzymes catalysing their degradation may involve a multi-enzyme complex of the biosynthetic enzymes, similar to those found in fungi by Giles and co-workers. Our data do not support this suggestion. Under conditions in which the polyaromatic biosynthetic enzyme complex is readily demonstrable in fungi (Giles et al. 1967a; Ahmed \& Giles, 1969), the $A$. calco-aceticus enzymes, like those of other bacteria, including species with and without the degradative pathway (Berlyn \& Giles, I969), were separable. The molecular weight values were similar to those for other bacteria included in that study, resembling most closely those for Pseudomonas aeruginosa and Streptomyces coelicolor. Although Tresguerres et al. (1972) observed a changed pattern of differential utilization of exogenous and DHQ-derived DHS in extracts prepared by sonic or lysozyme treatment, we observed similar sedimentation patterns of the biosynthetic enzymes extracted 
by the two procedures. Under a variety of extraction conditions the enzymes were not aggregated in vitro.

Our observation of two distinct peaks on sucrose gradients of quinate-grown bacteria, together with the inducibility and heat-lability of the lighter peak, are consistent with the previous observations by Ingledew et al. (I97I) of a quinate-induced isozyme distinguishable from synthetic dehydroquinase by thermal inactivation kinetics. Two dehydroquinase isozymes were described first in Neurospora crassa (Giles et al. 1967b) and subsequently in several fungi (Ahmed \& Giles, 1969). The inducible dehydroquinase of Acinetobacter calcoaceticus sedimented at a position corresponding to a molecular weight of approximately 40000. The enzyme which catalyses the preceding step in the degradative pathway, quinate (shikimate) dehydrogenase was found by Tresguerres, deTorrontegui, Ingledew \& Cánovas $(\mathrm{I} 970 \mathrm{~b})$ to be associated with a particulate fraction. Although we did not study this enzyme, in a single assay we found the enzyme in the crude extract (of quinate-grown bacteria), but not in gradients after high-speed centrifugation. Thus the dehydroquinase and dehydrogenase of the degradative pathway were also separable in vitro. However, the association of dehydrogenase with a particulate fraction suggests the possibility of a specialized localization of this reaction sequence within the bacterium.

Several lines of evidence have confirmed the existence of mechanisms regulating the flow of intermediates through the two pathways in Acinetobacter calco-aceticus: biosynthesis of aromatic amino acids continues in the presence of high levels of the hydroaromatic degradative enzymes, which can be induced gratuitously by $p$-hydroxybenzoic acid or PCA or maintained constitutively in PCA-accumulating mutants (Cánovas, Wheelis \& Stanier, I968); the biosynthetic dehydroquinase does not catalyse the degradation of exogenously supplied quinate in mutants lacking inducible dehydroquinase (Ingledew et al. 197I); the rate of formation of PCA from exogenously supplied DHS is greater than the rate of the DHS reductase reaction, whereas with DHS derived from conversion of exogenous DHQ by the biosynthetic dehydroquinase, the DHS reductase rate exceeds the DHS dehydrase rate at low substrate concentrations, with bacteria disrupted by lysozyme-osmotic shock treatment (Tresguerres et al. 1972). The induction of PCA-dependent enzymes in PCA oxygenase mutants grown on succinate at $30^{\circ} \mathrm{C}$ suggests some leakage from the biosynthetic pathway, leading to PCA accumulation at this temperature; at $20^{\circ} \mathrm{C}$ this does not occur (Cánovas et al. 1968).

In the absence of stable multi-enzyme complexes as found in fungi, alternate means of regulation in bacteria must be considered. In Acinetobacter calco-aceticus end-product induction by PCA of the hydroaromatic enzymes, as found by Cánovas et al. (1968) and Ingledew et al. (I97I), ensures that the biosynthetic intermediates do not induce enzymes which would catalyse their degradation, since only at very high levels of (exogenously supplied) quinate or shikimate in an uninduced wild-type bacterium will enough PCA be formed to induce the early degradative pathway enzymes. This mechanism and its occurrence in other pathways degrading important biosynthetic compounds is discussed by Cánovas et al. (1968). However, this method for restricting induction of the hydroaromatic enzymes is not universal among bacteria. The hydroaromatic pathway in Pseudomonas putida appears to be induced by DHS or its immediate precursors, rather than by PCA (Wheelis \& Stanier, 1970). This is similar to the substrate-induction implicated by Rines (I969) for Neurospora crassa. In Aerobacter aerogenes, the mode of induction of this pathway has not been elucidated. The continued synthesis of aromatic amino acids in bacteria with fully induced degradative enzymes may rely on favourable differences in reaction velocities and binding affinities of the enzymes for the common intermediates - although under many conditions 
DHS utilization appears to be an exception in this regard, and feedback inhibition of DHS dehydrase by PCA may be important (Tresguerres et al. 1972)-or it may involve a channelling mechanism not characterized by aggregation in vitro. It is possible that physical compartmentalization of the components of the two pathways may predominate, but be destroyed after disruption; indeed, stability of the known aromatic biosynthetic multienzyme complexes and activities of their individual components have been found to vary in different organisms (S. I. Ahmed and N. H. Giles, unpublished; Berlyn et al. 1970).

This work was supported by National Science Foundation Grant GB 13216, and was greatly facilitated by the technical assistance of $\mathrm{Mr} \mathrm{T}$. Blauvelt.

\section{REFERENCES}

Ahmed, S. I. \& GILES, N. H. (I969). Organization of enzymes in the common aromatic synthetic pathway: evidence for aggregation in fungi. Journal of Bacteriology 99, 23I-237.

BerLyn, M. B., AHMED, S. I. \& GiLes, N. H. (1970). Organization of polyaromatic biosynthetic enzymes in a variety of photosynthetic organisms. Journal of Bacteriology 104, 768-774.

BerLyN, M. B. \& Giles, N. H. (1969). Organization of enzymes in the polyaromatic synthetic pathway: separability in bacteria. Journal of Bacteriology 99, 222-230.

Cánovas, J. L., Wheelis, M. L. \& Stanier, R. Y. (I968). Regulation of the enzymes of the $\beta$-ketoadipate pathway in Moraxella calcoacetica. 2. The role of protocatechuate as inducer. European Journal of Biochemistry 3, 293-304.

Giles, N. H., CASE, M. E., PARTridge, C. W. H. \& Ahmed, S. I. (I967a). A gene cluster in Neurospora crassa coding for an aggregate of aromatic synthetic enzymes. Proceedings of the National Academy of Sciences of the United States of America 58, I453-I460.

Giles, N. H., Partridge, C. W. H., Ahmed, S. I. \& Case, M. E. (1967b). The occurrence of two dehydroquinases in Neurospora crassa, one constitutive and one inducible. Proceedings of the National Academy of Sciences of the United States of America 58, 1930-1937.

Ingledew, W. M., Tresguerres, M. E. \& Cánovas, J. L. (I97I). Regulation of the enzymes in the hydroaromatic pathway in Acinetobacter calco-aceticus. Journal of General Microbiology 68, 273-282.

Ornston, L. N. \& STANiER, R. Y. (1966). The conversion of catechol and protocatechuate to $\beta$-ketoadipate by Pseudomonas putida. I. Biochemistry. Journal of Biological Chemistry 241, 3776-3786.

RINES, H.W. (1969). Genetical and biochemical studies on the inducible quinic acid catabolic pathway in Neurospora crassa. Ph.D. Dissertation, Yale University.

Tresguerres, M. E. F., deTorrontegui, G. \& Cánovas, J. L. (i970a). The metabolism of quinate by Acinetobacter calco-aceticus. Archiv für Mikrobiologie 70, I I0-1 18.

Tresguerres, M. E. F., DeTorrontegui, G., InGledew, W. J. \& Cánovas, J. L. (1970 b). Regulation of the $\beta$-ketoadipate pathway in Moraxella. Control of quinate oxidation by protocatechuate. European Journal of Biochemistry 14, 445-450.

Tresguerres, M. E. F., Ingledew, W. M. \& Cánovas, J. L. (I972). Potential competition for 5-dehydroshikimate between the aromatic biosynthetic route and the catabolic hydroaromatic pathway. Archiv für Mikrobiologie 82, I I I-I 19.

Wheelis, M. L. \& Stanier, R. Y. (I970). The genetic control of dissimilatory pathways in Pseudomonas putida. Genetics 66, 245-266. 